University of Nebraska - Lincoln

DigitalCommons@University of Nebraska - Lincoln

1993

\title{
Effects of Response Strategy and Retention Interval on Performance of Clark's Nutcrackers in a Radial Maze Analogue
}

Deborah J. Olson

University of Nebraska-Lincoln

Alan C. Kamil

University of Nebraska-Lincoln

Russell P. Balda

Northern Arizona University

Follow this and additional works at: https://digitalcommons.unl.edu/bioscibehavior

Part of the Behavior and Ethology Commons

Olson, Deborah J.; Kamil, Alan C.; and Balda, Russell P., "Effects of Response Strategy and Retention Interval on Performance of Clark's Nutcrackers in a Radial Maze Analogue" (1993). Papers in Behavior and Biological Sciences. 76.

https://digitalcommons.unl.edu/bioscibehavior/76

This Article is brought to you for free and open access by the Papers in the Biological Sciences at DigitalCommons@University of Nebraska - Lincoln. It has been accepted for inclusion in Papers in Behavior and Biological Sciences by an authorized administrator of DigitalCommons@University of Nebraska - Lincoln. 
Published in Journal of Experimental Psychology: Animal Behavior Processes19:2 (1993), pp. 138-148; doi: 10.1037/0097-7403.19.2.138

Copyright ( 1993 American Psychological Association. Used by permission. "This article may not exactly replicate the final version published in the APA journal. It is not the copy of record." http://www.apa.org/journals/abp/

These experiments were reported at the annual meeting of the Animal Behavior Society, University of North Carolina at Wilmington, June 1991. This research was supported by Public Health Services Grant MH44200. We thank Curt Dimmick, Nancy Stotz, Sally Good, and many others too numerous to mention for their help with data collection. We thank three anonymous reviewers from Journal of Experimental Psychology: Animal Behavior Processes for their helpful comments.

\title{
Effects of Response Strategy and Retention Interval on Performance of Clark's Nutcrackers in a Radial Maze Analogue
}

\author{
Deborah J. Olson, ${ }^{1}$ Alan C. Kamil, ${ }^{1}$ Russell P. Balda ${ }^{2}$ \\ 1. School of Biological Sciences, University of Nebraska - Lincoln \\ 2. Department of Biological Sciences, Northern Arizona University \\ Corresponding author - Deborah J. Olson, School of Biological Sciences, \\ Manter Hall, University of Nebraska-Lincoln, Lincoln, Nebraska 68588-0118
}

\begin{abstract}
Two groups of Clark's nutcrackers (Nucifraga columbiana) were trained to use either a stay or shift response strategy in a radial maze analogue. Each trial had a preretention stage, a retention interval, and a postretention test. In Experiment 1, acquisition with a 5-min retention interval was studied. Response strategy did not affect the rate at which the task was learned. Performance following longer retention intervals was tested in Experiments 2-4. Changes in retention intervals were presented in trial blocks of increasing duration in Experiment 2 and were randomly presented between trials in Experiment 3. Experiment 4 extended the retention interval to 24 hr. No difference in performance was found between the 2 groups in any of these experiments. These results suggest a flexible relationship between spatial memory and response requirement in food-hoarding birds for at least 1 spatial memory task.
\end{abstract}

The purpose of these experiments was to investigate in detail the radial maze performance of Clark's nutcrackers $(\mathrm{Nu}$ cifraga columbiana). In nature, Clark's nutcrackers cache thousands of pine seeds every fall and recover them throughout the winter and spring. A series of field and laboratory studies have shown that nutcrackers use spatial memory to relocate their caches (see Kamil \& Balda, 1990, for review). Because recovered seeds are essential to survival and reproduction, the biological success of nutcrackers is closely linked with their ability to remember the locations of cache sites. This relationship between memory and biological success has led to many studies of the memory abilities of nutcrackers in a number of experimental paradigms.

Initial studies concentrated on cache-recovery tests of spatial memory and demonstrated that nutcrackers performed extremely well. For example, they still remembered cache locations 285 days after creating them (Balda \& Kamil, 1992). In addition, a number of studies were conducted using more traditional psychological tests of memory. Olson (1991) used operant procedures and found that nutcrackers consistently performed at higher levels than pigeons and scrub jays in a spatial delayed nonmatching-to-sample task. Balda and Kamil (1988) found that Clark's nutcrackers performed well after retention intervals as long as 6-8 hr in an openroom analogue of the radial maze task. These levels of performance compare favorably with those of rats (Rattus norvegicus) tested under similar conditions (Beatty \& Shavalia, 1980) and are better than results obtained in open-room analogues with pigeons (Columba livia, Roberts \& Van Veldhuizen, 1985; Spetch \& Edwards, 1986; Spetch \& Honig, 1988). The performance of Clark's nutcrackers in these noncaching tests of spatial memory was particularly important because it addressed the issue of the cross-situational generality of the abilities of nutcrackers.

Another important issue is the possible effects of different response strategies on performance. In a number of studies, the effects of win-stay and win-shift strategies have been examined with a variety of paradigms and different species. Some of these studies have found superior performance when animals were required to shift their response away from a site at which a reward was obtained. In a Tmaze task, Olson and Maki (1983) found that pigeons required to shift performed better than those required to stay. Birds in the stay group rarely performed above chance. This is consistent with the performance of Siamese fighting fish (Betta splendens) in a Y maze, (Roitblat, Tham, \& Golub, 1982). Overman, McLain, Ormsby, and Brooks (1983) found that squirrel monkeys (Saimiri sciureus) learned a visual object task more rapidly when they were required to select a new object (shift) than when they were required to select the same object. Sacks (1973) found that blue jays (Cyanocitta cristata) learned color nonmatching (shift) faster than matching (stay) in an operant chamber.

In some studies, attempts have been made to examine the connection between natural history and response strategies by studying nectar-feeding birds (e.g., sunbirds [Nectarinia spp], Gill \& Wolf, 1977; amakihi [Loxops virens], Kamil, 1978). These birds deplete the flowers they feed on, suggesting that shift might be easier to learn than stay. Cole, Hainsworth, Kamil, Mercier, and Wolf (1982) found that adult hummingbirds (Archilochus alexandri, Eugenes fulgens, and Lampornis clemensiae) learned to shift away from a rewarded location much more readily than they learned to return to it. This is consistent with the species' natural history, in which 
individual flowers are depleted when visited. Similar results were obtained by Wunderle and Martinez (1987) with adult, wild-caught nectarivarous bananaquits (Coereba flaveola). However, when handreared juvenile bananaquits were tested, there were no significant differences in the readiness with which the birds learned the two strategies.

There is some evidence that learning a response strategy depends on the distribution of food. Herrmann, Bahr, Bremner, and Ellen (1982) used a complex three-table paradigm and found that when experienced rats were allowed to explore the maze and were removed before food was depleted they learned to stay, but when the food was depleted they learned to shift. In contrast, Olson and Maki (1983) found that performance of pigeons in a T maze was unaffected by depletion. Pigeons learned the shift strategy better under both depletion and nondepletion conditions.

The natural history of the nutcracker indicates that these birds use a variety of response options in the field. These options would be used to guide behavior in different situations, thus decreasing the number of errors and increasing the efficiency of the birds. For example, they must return to cache sites to retrieve seeds. This implies that a stay strategy is used. However, once a nutcracker has removed seeds from a cache site, it tends to avoid emptied cache sites compared with unharvested cache sites (Kamil, Balda, Olson, \& Good, in press). This implies a shift strategy. Although considerations of natural history produce no obvious prediction based on exclusive use of a single strategy, one possibility may be that the strategy the bird prefers to use depends on whether seeds were placed into or removed from a site. In that case, shift strategies would be preferred in the radial maze procedures during which seeds are removed from the to-be-remembered locations.

In Experiment 1, we examined the effects of stay versus shift response strategies on the acquisition of the radial task. In Experiments 2, 3, and 4, we examined performance after long retention intervals.

\section{Experiment 1}

\section{Method}

Subjects - Ten Clark's nutcrackers served as subjects. The birds had been captured as adults and were of unknown sex and age. Four birds had been in captivity for 5 or 6 years. Five birds had been in captivity almost 2 years, and the last bird had been in captivity under 1 year. These birds had previous experience in cache-recovery experiments but had never been tested in radial maze analogue procedures. They were individually housed in large cages and were maintained on a 10:14-hr light-dark cycle. The birds were maintained at $85-90 \%$ of their free-feeding weights with controlled daily feedings of turkey starter, pigeon pellets, crushed corn, sun-flower seeds, pine seeds, and mealworms.

Apparatus - The experiment was conducted in a room 2.7 $\mathrm{m}$ high $\times 3.2 \mathrm{~m}$ wide $\times 3.6 \mathrm{~m}$ long. The east wall contained a door, a one-way window, and a porthole. The porthole served as the entry and exit to the room for the birds. The raised plywood floor contained 12 holes, $5.1 \mathrm{~cm}$ in diameter, drilled in a circular arrangement around the center of the false floor. The distance between the centers of adjacent holes was $58.4 \mathrm{~cm}$.
Each hole could be fitted with either a paper cup filled with fine sand or a wooden plug. A large perch was located near the center of the circle of holes so that the distance between the perch and individual holes ranged between $107.9 \mathrm{~cm}$ and 119.9 $\mathrm{cm}$. Spatial cues were provided by posters placed on the north, south, and west walls and by objects placed on the floor, such as rocks, wooden logs, and cinder blocks. Objects were placed between all pairs of adjacent holes to discourage stereotyped choice of adjacent sites (Balda \& Kamil, 1988).

\section{Procedure}

Habituation - During habituation, the holes for the radial maze were made unavailable for exploration by fitting them with wooden plugs. First, the birds were familiarized with the radial maze room. A session lasted $30 \mathrm{~min}$, and no pine seeds were available. The activity level of the bird was monitored through the one-way mirror. This stage ended when the bird was freely moving around and exploring the room $(M=3.2$ days, range $=2-5$ days). This was followed by a single session with six pine seeds spread on the apparatus floor, within the radial maze boundaries. The session ended when the bird had consumed the seeds.

Pretraining - Prior to the start of pretraining, the birds were randomly divided into two groups, stay and shift, with 5 birds per group (see later for definition of groups). Pretraining was given to prepare the birds to search for buried seeds from the sand-filled cups. The birds received one trial per day for 4 days. Four of the 12 holes were randomly assigned for each trial. For the duration of the experiment any unused holes, those holes that did not contain a sand-filled cup, were fitted with plugs, making them inaccessible.

Each trial consisted of two stages. During the first stage, two holes were filled with sand cups. A pine seed was placed on top of each cup. The bird was transported in its home cage to the porthole and released into the room. The bird was allowed to remove and eat each of the pine seeds. Visits to holes were recorded by the experimenter observing the bird through the oneway mirror. The room light was extinguished when the last seed was eaten, forcing the bird to quit searching. The only light in the room came through the porthole and served as a guide to allow the bird to return to the home cage. Generally, the bird returned to the home cage on its own, but occasionally the experimenter would have to enter the room to encourage the bird to leave through the porthole.

After the bird returned to the home cage, the experimenter entered the room, cleaned up any sand that was displaced by the bird, and prepared the cups for the second stage of the trial, which began $5 \mathrm{~min}$ after completion of the first stage. During the second stage, four holes were fitted with sand cups, the two holes used during the first stage and two randomly selected new holes. A pine seed was placed on top of two of the cups. The stay group had pine seeds placed on top of the same holes used during the first stage. The shift group had pine seeds placed on top of the two newly opened sand cups. The bird reentered the room and removed and ate the pine seeds. All visits to cups were recorded. The room light was extinguished when the last seed was eaten.

Over the next 3 days, the pine seeds were gradually buried in the sand until, during Day 4 of pretraining, only a very small portion of each seed was exposed during either stage of the trial. 
Two/four-hole acquisition - Acquisition of the radial maze analogue began the day after pretraining ended. All procedures were identical with those of pretraining except that pine seeds were completely buried about $1 \mathrm{~cm}$ below the surface of the sand. Each trial consisted of a preretention stage, a 5 -min retention interval, and a postretention test stage. Four holes were randomly assigned for each trial, and two of these four holes were randomly selected as the holes to be exposed during the preretention stage. At the start of preretention, two holes had sand cups in them with a pine seed in each cup, and all other holes were capped. The bird entered the room through the porthole and was allowed to probe the cups until all seeds had been removed. A hole was considered to have been visited whenever the bird probed a hole, that is, brought its beak into contact with the surface of the sand. The room lights were extinguished after the last seed was eaten.

During the 5-min retention interval, the experimenter entered the room and cleaned up any sand that had been tossed out of the cups. Two additional sand cups were placed in the remaining two holes assigned for the trial. Pine seeds were buried in the appropriate cups depending on the group assignment: old holes for the stay group and new holes for the shift group. At the end of the retention interval, the bird returned to the room for the postretention test, which ended after the bird had removed all seeds or four probes had been made. These four probes need not have been to four different holes. Two/four-hole acquisition continued for 60 trials, 1 trial per day, 6 trials per week.

Four/eight-hole acquisition - The procedures used during four/eight-hole acquisition were identical with those used during two/four-hole acquisition except for the number of holes used. Four randomly selected holes were opened, with a seed in each, during the preretention stage. The preretention stage ended when the bird had removed all four seeds. The four holes from preretention plus four randomly selected new holes were opened during the postretention test. For stay birds, the four seeds were placed in the old holes. For shift birds, the seeds were placed in the four new holes. The postretention test began after the 5-min retention interval and ended when the bird had either removed all the seeds or probed six different holes. Each bird received 1 trial per day, 6 trials per week for 10 weeks (60 trials).

\section{Results}

The nutcrackers adapted to the task quite readily. There were no differences between the performance of the stay and shift groups during the two/four-hole or four/eight-hole conditions. The performance of the shift group at the end of the two/four-hole condition was reliably above chance, but the performance of the stay group was not. Performance of both groups was above chance throughout the four/eighthole condition.

All 10 birds completed pretraining in the 4 days allotted. In general, they required only a few minutes to complete either pre- or postretention stages of a trial. All data analyses for this experiment and all subsequent experiments used only first probes to a hole during the postretention test stage. This was because when the birds probed a hole for seeds, they did so quite vigorously, leaving highly visible signs of digging around the hole. This scattered sand made holes already visited during the postretention stage quite different in appearance from unvisited holes. Second visits to holes during postretention testing were quite rare $(<1 \%)$.

Separate analyses were conducted on the data from the two/four- and the four/eight-hole conditions. In each case, the data for each bird were averaged over quarters of the training, in blocks of 15 sessions each, and a mixed analysis of variance (ANOVA) was carried out, with groups as the between-subject factor and quarters as the within-subject factor. The percentage of correct probes (digs in sand cups) was calculated for the first two probes in the two/four-hole condition and the first four probes in the four/eight-hole condition (so that chance performance equaled 50\%). Percentage correct was used for all analyses throughout. (Analyses were also performed using logit transformations, but the transformation had no effect on the results). An alpha level of $p \leq .05$ was adopted for all statistical analyses for all experiments, and all significant results are reported.

There were no significant differences between the performance of the stay and shift groups during the two/four-hole condition, $F(1,8)=2.85$ (see Figure 1). Performance did not improve significantly as two/four-hole training proceeded, $F$ $(3,24)=1.45$. Acquisition of the two/four-hole condition was not affected by the response strategy used, $F(3,24)=2.48$.

Eight one-tailed $t$ tests were conducted for each group at each quarter and compared with chance (50\%). The performance of the stay group was above chance during the first quarter and the third quarter. The performance of the shift group was above chance during the last three quarters of the two/four-hole condition.

One nutcracker failed to complete one trial in the first quarter in the four/eight-hole condition. The data for this trial were not included in the analysis reported. Once again there were no significant differences in the performance for the stay and shift groups in the four/eight-hole condition or in the interaction between the groups and quarter ( $F \mathrm{~s}<$ $1)$. There was a significant improvement in performance as training proceeded, $F(3,24)=5.25$. Performance improved fairly dramatically between Quarters 1 and 2 and remained stable thereafter. At the end of the four/eight-hole condition, the percentages correct were about $80 \%$ and $75 \%$ for the shift and stay groups, respectively (see Figure 1). Eight one-tailed $t$ tests, four per group, were conducted and compared with chance $(50 \%)$. Both groups consistently performed above chance throughout the four/eight-hole condition.

\section{Discussion}

The major result of Experiment 1 was that nutcrackers could learn to either return to or shift away from the preretention sites. Although there were no statistically reliable differences between the groups, there were indications that initial acquisition was more rapid for the shift group than for the stay group. The shift group was more consistently above chance than the stay group during the two/four-hole condition. In addition, in the analysis of two/four-hole performance, the Group $\times$ Quarter interaction approached significance $(p<.10)$. These data suggest that there was a difference between the groups during the two/four-hole condition, but the question of group differences early in acquisition must be regarded as unresolved at this time. 


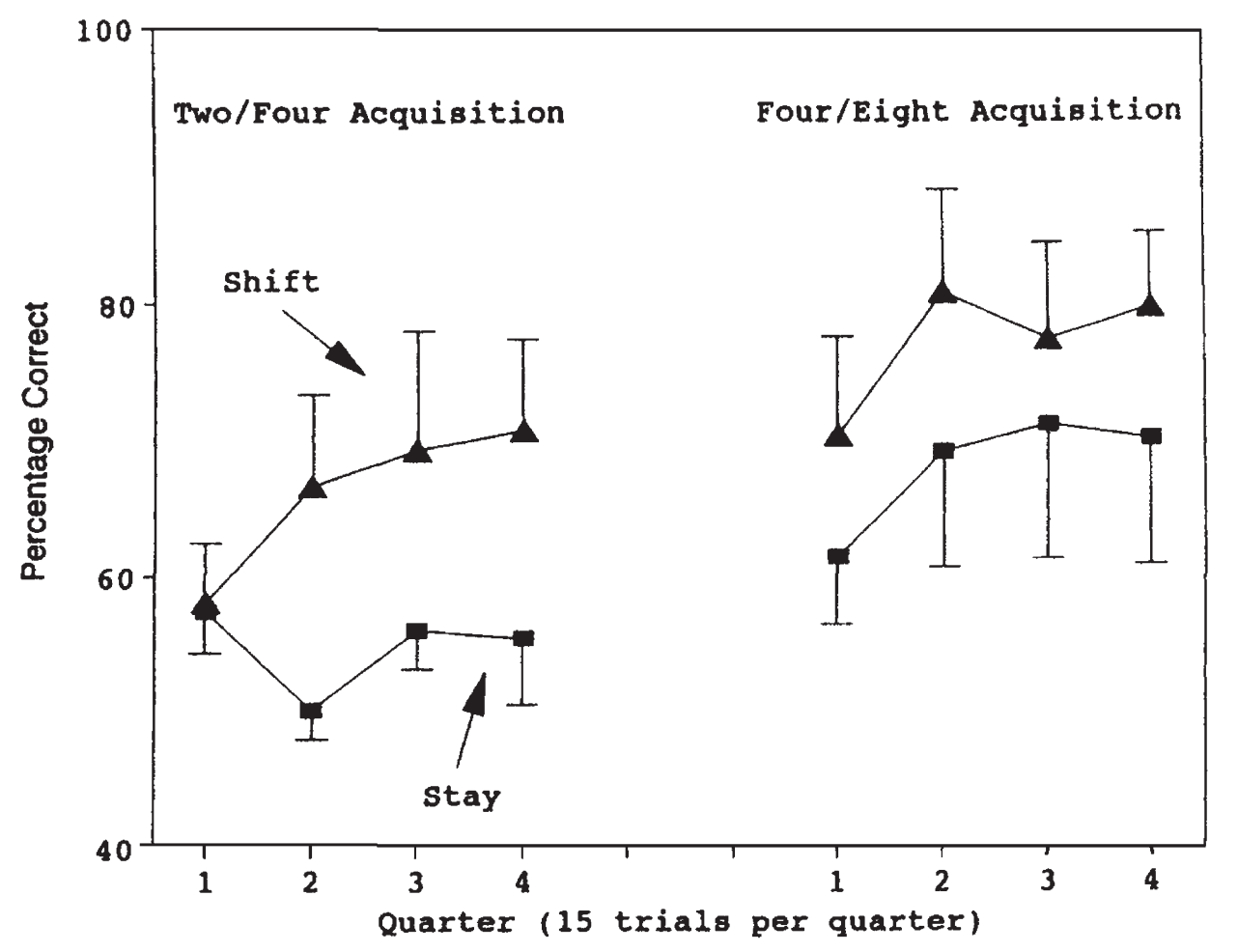

Figure 1. Percentage correct ( \pm SE , as indicated by bars) for the stay and shift groups following a 5-min retention interval in Experiment 1 . (Percentage correct was averaged for the first two probes for the two/four-hole acquisition and for the first four probes for the four/eight-hole acquisition. Each quarter represents the mean of 15 trials.)

Acquisition proceeded rapidly for both the stay and shift groups during the four/eight-hole condition. Both groups performed at levels that were above chance, and there were no differences between the performance of the groups. It is not clear why the change to the four/eight-hole condition resulted in such rapid improvement in accuracy. Perhaps the events associated with entering and leaving the test room were disruptive. In that case, the longer times spent in the room during the pre- and postretention stages during the four/eight-hole condition may have reduced the extent of this disruption. This would make remembering preretention events easier and might facilitate postretention behavior.

Although the stay group consistently performed at levels slightly below the shift group during the four/eight-hole condition, this difference never approached significance. Thus, there may have been effects resulting from different response strategies early in training, but these effects were transitory. This is in contrast to a number of other studies that have found differences, as discussed in the introduction. Many of these studies found better shift learning than stay learning. This result is particularly interesting because the conditions of the study were such that it could be argued that the stay group had a more difficult task than the shift group.

The stay and shift conditions differ in what might be termed their consistency. Consider the situation of a bird that has recovered all but one of its seeds during the test stage. A shift bird must avoid all holes visited, whether those holes were visited in preretention or during the postretention test. In contrast, a stay bird must return to the holes visited preretention but avoid the holes already sampled earlier during the postretention test. Although there were clear cues available to assist the birds in avoiding the already visited holes during the postretention test, this simultaneous requirement to stay with respect to some holes and shift for others may have made the stay task more difficult to acquire. This might be especially true during testing in which relatively few holes exposed each day, as during two/four-hole testing.

Despite this difference in the consistency of the strategy required, the two groups learned their tasks to levels of performance that were not statistically different. Thus, these data clearly demonstrate that Clark's nutcrackers were fully capable of learning to use either stay or shift strategies in the radial maze task.

\section{Experiment 2}

The purpose of Experiment 2 was to test the performance of the stay and shift birds extensively with different retention intervals. There were two reasons for this. First, the question of exactly how well the nutcrackers perform after long retention intervals when using different response strategies was of inherent interest. Olson (1991) found that nutcrackers performed exceptionally well after long intervals (60-80 s) in operant spatial nonmatching-to-sample. Second, although there were no differences between the stay and shift groups at the end of training with the 5-min retention interval, if performance after long retention intervals varies depending on the response required, differences between the stay and shift groups might appear during retention testing. 


\section{Method}

Subjects and Apparatus - The birds trained in Experiment 1 also served in Experiment 2. They were maintained the same way as during Experiment 1 and were tested in the same experimental room.

\section{Procedure}

The procedures of the four/eight-hole condition described in Experiment 1 were used throughout Experiment 2 except for the manipulation of retention intervals described later. Each bird received one trial per day, 5-6 days/week.

Testing began immediately after the completion of the four/eight-hole condition of Experiment 1. Four retention intervals $(45,90,180$, and $360 \mathrm{~min})$ were used and were presented in increasing order. Each retention interval was presented for a block of 20 trials.

\section{Results}

The performance of the stay and shift groups declined as the retention interval increased, and there were no differences between the groups in the rate of forgetting. Consistent with Experiment 1, there were no differences between the performance of the groups. To analyze the data the percentage of correct probes in the first four visits to holes during the postretention test was calculated for each bird. This measure of percentage correct was used for all subsequent exper- iments. In preliminary analyses, the data for each retention interval were divided into four quarters of 5 trials each. The results of a Group $\times$ Quarter analysis indicated that neither the main effect of quarter nor the interaction of Quarter $\times$ Retention Interval were significant. However, the data tended to be somewhat more variable when a new retention interval was first introduced. Therefore, the data from the last 10 trials of each retention interval were used to compare performance between different retention intervals.

A Group $\times$ Retention Interval ANOVA revealed no significant difference between the performance of the stay and shift groups, $F(1,8)=1.27$. Performance decreased as the retention interval increased, $F(3,24)=4.70$ (see Figure 2). A post hoc Newman-Keuls test revealed that only the $360-$ min interval differed significantly from all shorter retention intervals, which did not differ among themselves. The response strategy used did not have any differential effect on performance during different retention intervals, $F(3,24)=1.26$.

\section{Discussion}

These results demonstrate that the ability of Clark's nutcrackers to remember visited locations in the radial maze analogue was unaffected by response strategy. Thus, the ability of Clark's nutcrackers to perform well after long retention intervals (Balda \& Kamil, 1988) was apparent whether the birds were required to shift away from or return to sites visited before the retention interval.

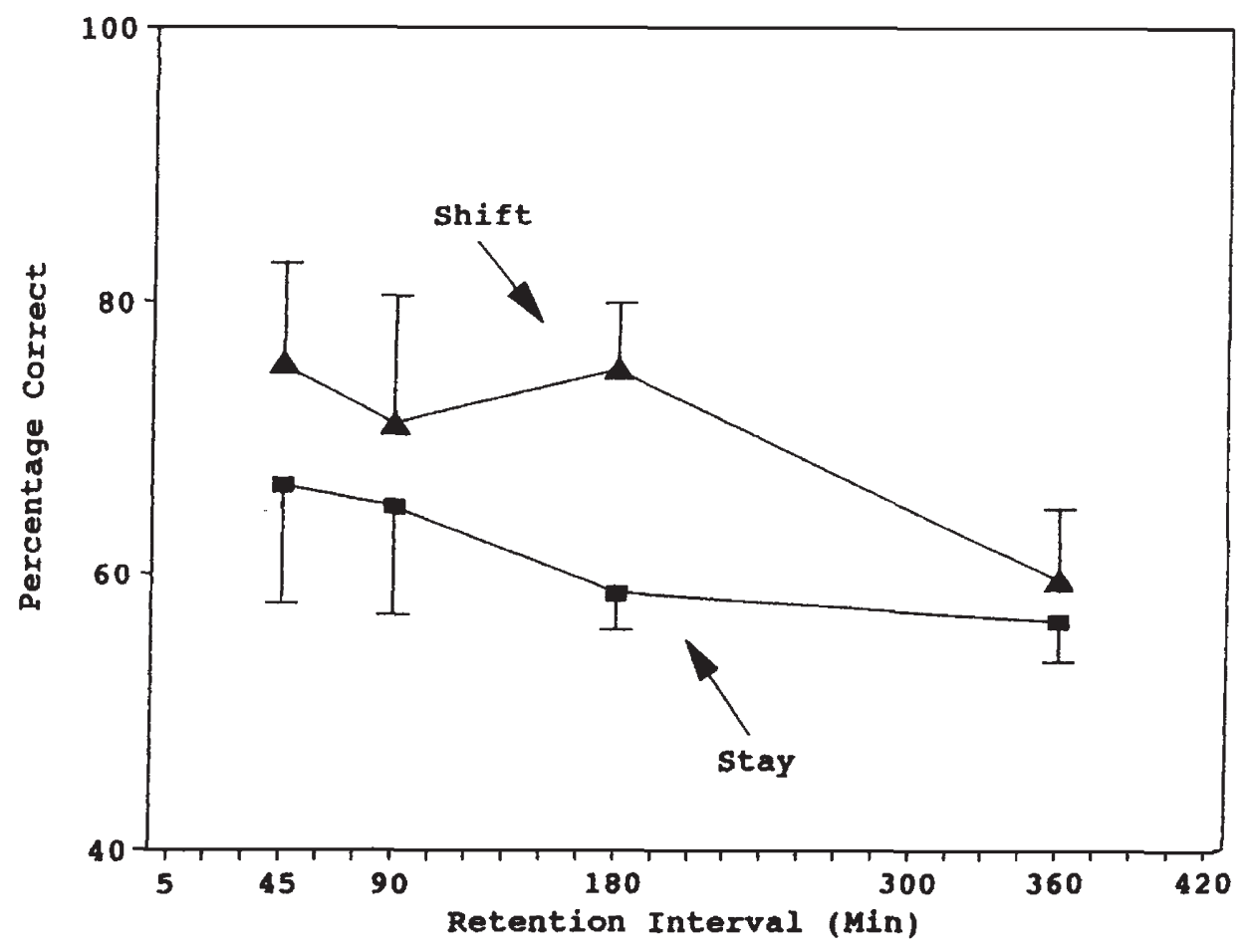

Figure 2. Percentage correct ( $\pm \mathrm{SE}$, as indicated by bars) for the stay and shift groups for the first four probes following the retention interval. (Averages were for the last 10 trials of each block. Three retention intervals [5, 300, and $420 \mathrm{~min}]$ were not presented in Experiment 2 . These were included to allow direct comparisons with Figure 3.) 


\section{Experiment 3}

An advantage of the procedure used during Experiment 2 was that the gradual increases in retention intervals allowed the birds time to habituate to sequentially longer intervals. However, there was an accompanying disadvantage: Comparisons among retention intervals were confounded with order of testing. That is, the birds were necessarily more experienced with the procedures when tested at the longer retention intervals. Therefore, Experiment 3 was carried out to remove this confound.

\section{Method}

Subjects and Apparatus - The birds trained in Experiments 1 and 2 also served in Experiment 3. They were maintained the same way as during the previous experiments and were tested in the same experimental room.

\section{Procedure}

The procedures of Experiment 3 were identical with those of Experiment 2 except for the retention intervals used for testing and the manner in which those intervals were scheduled. Testing began immediately after the completion of Experiment 2. Five retention intervals $(5,45,180,300$, and $420 \mathrm{~min})$ were used. There were five trials per week, and each of the five intervals was tested once per week. The order of testing of the retention intervals varied randomly from week to week. This testing continued until 80 trials, 16 trials for each retention interval, had been conducted.

\section{Results}

As the retention interval increased, performance for the stay and shift groups decreased. There were no differences between the stay and shift groups in either performance or rate of forgetting. In preliminary analyses, the data for each retention interval were divided into four quarters of 4 trials each. The results of a Group $\times$ Quarter analysis indicated that there was a significant effect of quarter, $F(3,24)$ $=3.81$. This was almost entirely due to an improvement from the first to the second quarter of testing, as the birds became accustomed to the daily variation in retention interval. Therefore, the data from the last 40 trials of Experiment 3 were used to compare performance after different retention intervals.

As during Experiment 2, there were no significant differences between the performance of the stay and shift groups, $F(1,8)=3.16$, nor was there a significant Group $\times$ Retention Interval interaction, $F(4,32)<1$. However, there was a significant decline in performance as the retention interval increased, $F(4,32)=17.47$ (see Figure 3). A subsequent post hoc Newman-Keuls test found that performance did not begin to decline until after the 45-min retention interval. Fol-

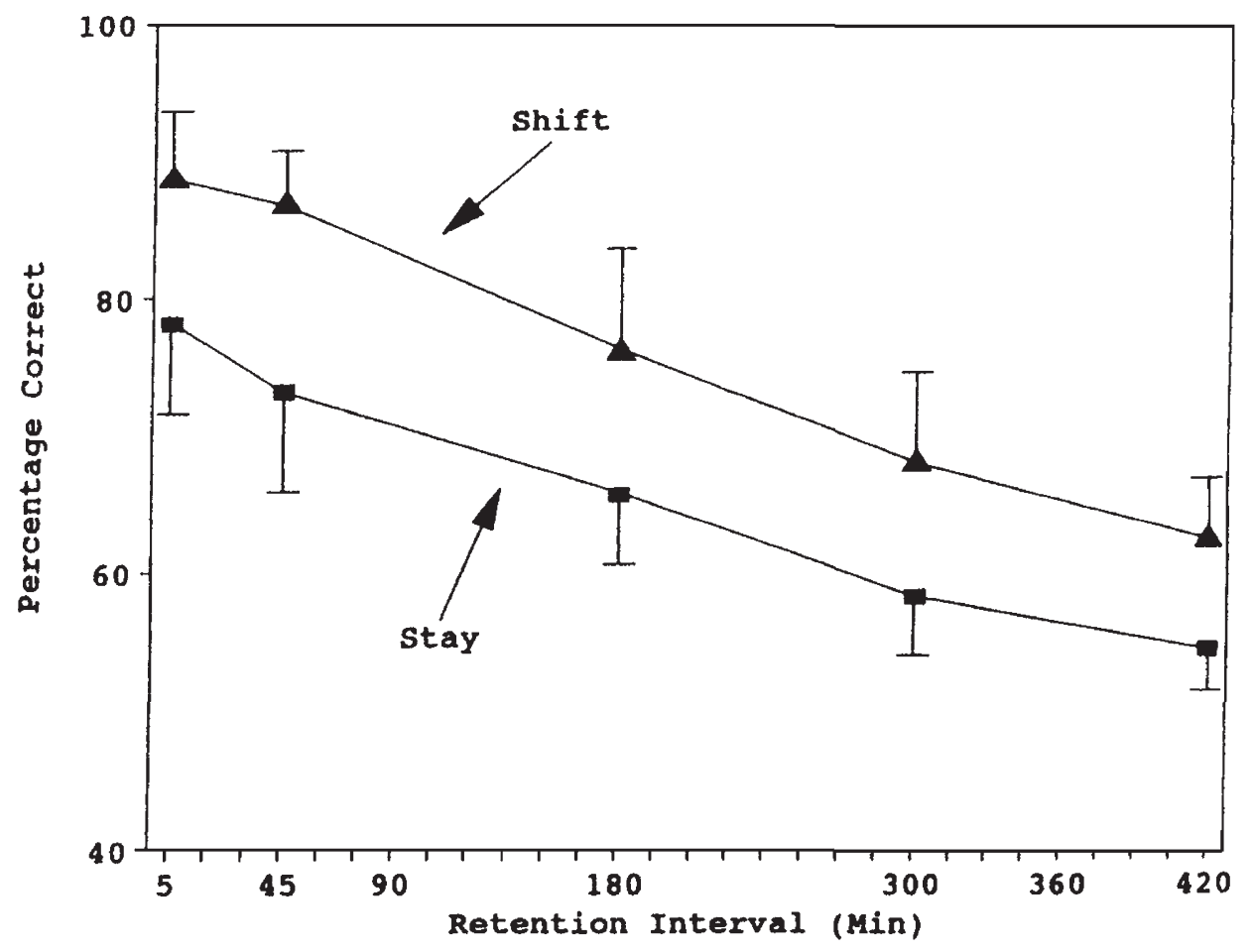

Figure 3. Percentage correct $( \pm \mathrm{SE}$, as indicated by bars) for the stay and shift groups for the first four probes following the retention interval. (Five retention intervals were presented in random order. The averages were for the last eight trials for each interval. Two retention intervals [90 and $360 \mathrm{~min}]$ were not presented in Experiment 3. These were included to allow direct comparisons with Figure 2 .) 
lowing this interval performance continued to decline, although there was no difference between the 300-min and 420-min retention intervals.

Because of the procedural limitations of this task it was not possible to use retention intervals shorter than $5 \mathrm{~min}$. However, some errors are expected even when very short intervals are used. If the performance observed at the 5-min retention interval represents the best estimate of performance, then performance for all other retention intervals can be calibrated against performance at the 5-min retention interval. The adjusted percentage correct scores were obtained by dividing the percentage correct at each of the longer retention intervals by the percentage correct at the 5-min interval using the last eight trials for each retention interval. The adjusted percentages were subjected to the same ANOVA as the raw percentages. Consistent with the raw percentage correct analyses, there was no significant difference between the performance of the stay and shift groups $(F<1)$. Performance decreased as the retention interval increased, $F(3,24)$ $=18.30$ (see Figure 4). A post hoc Newman-Keuls test found significant differences in performance between all pairs of retention intervals except $300 \mathrm{~min}$ and $420 \mathrm{~min}$.

Three of the retention intervals used in mixed testing had been used during either Experiment 1 ( 5 min) or Experiment 2 (45 and $180 \mathrm{~min}$ ). The performance during the last half of each condition was compared to determine if either experience or method of presentation for retention intervals, or both, affected performance. Two ANOVAs were performed, one for the 5-min interval (Experiment 1, four/eight-hole condition, and Experiment 3) and another for the 45-min and 180-min intervals (Experiments 2 and 3). The ANOVA comparing performance after a 5-min retention interval during Experiments 1 and 3 revealed neither a significant difference between groups nor a significant Groups $\times$ Experiment interaction. However, performance was better during Experiment $3(83.4 \%)$ than during Experiment $1(74.3 \%), F(1,8)=6.52$.

The ANOVA comparing performance after the 45-min and 180-min retention intervals during Experiments 2 and 3 used group as the between-subjects variable and retention interval and experiment as within-subjects variables. Neither the main effects nor the interactions were significant. It should be noted that performance was higher during Experiment 3 (75.5\%) than during Experiment 2 (68.9\%).

\section{Discussion}

The results of Experiment 3 show that different response strategies did not affect the ability of nutcrackers to remember spatial locations. When the accuracy of the two groups was adjusted to take into account the small differences in performance after a 5-min retention interval, there was no difference in accuracy after longer retention intervals. Thus, it seems most unlikely that different response strategy requirements affect forgetting.

It was not entirely unexpected that the performance at the 5-min retention interval in Experiment 3 was better than at the end of Experiment 1. The birds were not only more experienced with the procedure but also had made contact with

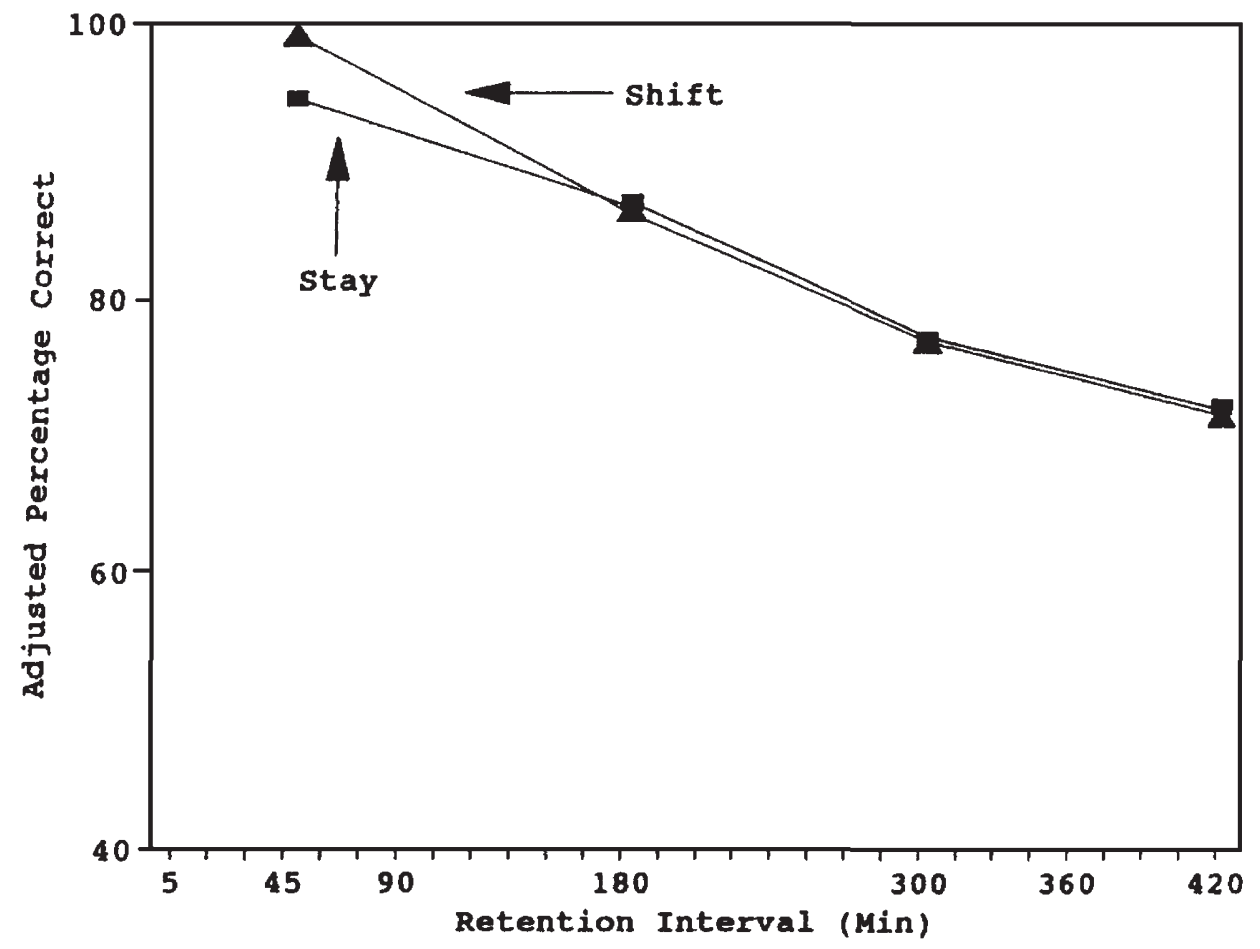

Figure 4. Adjusted percentage correct for first four probes at retention intervals greater than 5 min in Experiment 3 . (Adjusted percentage correct scores were obtained by dividing the percentage correct at each of the longer retention intervals by the percentage correct at the 5-min interval, using the last eight trials for each retention interval. Scaling of the x-axis is consistent with Figure 3 .) 
longer retention intervals. As noted in Experiment 2, performance tended to be more variable when a new retention interval was introduced. If the birds had to learn about longer retention intervals, then a change in the way the information was either coded or stored could occur. This could lead to an improvement in performance at the shortest interval.

What was more interesting was that performance for at least two retention intervals, $45 \mathrm{~min}$ and $180 \mathrm{~min}$, appeared to have stabilized by the end of Experiment 2. The continued and random contact with these retention intervals experienced in Experiment 3 did not disrupt performance. Although there was a trend toward improved performance when retention intervals were randomly presented, even if a difference had been obtained it would not have been possible to distinguish whether the improvement was due to either randomization of retention intervals or continued experience with the task.

\section{Experiment 4}

Balda and Kamil (1988) found that nutcrackers performed slightly above chance after 24-hr retention intervals. Hilton and Krebs (1990), using a similar procedure with parids, found that only the caching species show any reliable tendency to be above chance after $24 \mathrm{hr}$. In addition, rats were not above chance after 24-hr testing (Beatty \& Shavalia, 1980). Therefore, in Experiment 4 we tested the nutcrackers with a 24-hr retention interval.

\section{Method}

The two groups of birds from Experiment 3 were tested in the radial maze room used in the previous experiments. The 24-hr testing began immediately after the completion of Experiment 3 . The preretention and postretention stages of the trial were conducted the same way as they were throughout Experiments 2 and 3. During the retention interval, the birds were returned to the colony room and were fed at the standard feeding time. The post-retention test was conducted the next day at approximately $( \pm 15 \mathrm{~min})$ the same time the preretention stage had been started. For the first 29 trials, 3 trials per week were conducted. That is, the birds received either a pre- or postretention session 6 days per week and were laid off 1 day per week. Under these conditions, the intertrial interval between the postretention test of one trial and the preretention stage of the next trial was $24 \mathrm{hr}$ twice per week and $48 \mathrm{hr}$ once per week. Six nutcrackers, three from each group, received an additional 18 trials, during which testing was carried out just once per week, with a retention interval of 24 hr and an intertrial interval of 6 days.

\section{Results}

When data for both groups of birds were combined, performance was better than chance for both 24-hr conditions. Results were mixed for individual groups. One nutcracker, Koenig, completed only 28 trials during the three-timesper-week $(3 \times)$ condition. In the one-time-per-week $(1 \times)$ condition, two nutcrackers made only two visits during the postretention test. This occurred for one trial for Helga and for two trials for Klaus. Preliminary analyses found that performance did not change across trials during either 24-hr condition, so all data were used in the analyses reported.

Separate ANOVAs revealed that there were no significant differences between the stay and shift groups during either 24-hr condition ( $F<1$ in each case). An additional ANOVA was carried out to compare performance during the $1 \times$ and $3 \times$ conditions for the 6 birds tested under each condition (ignoring group differences). Performance did not differ significantly between the two $24-\mathrm{hr}$ conditions $(F<1)$.

Two analyses were conducted comparing the performance of the birds with chance expectations. For these analyses, one-tailed tests were used, and the chance level of performance was compared with $50 \%$. First, the binomial distribution was used to evaluate the performance of individual birds, resulting in 16 binomial tests (see Tables 1 and 2). Only two of these 16 tests were significant. Second, $t$ tests were used to evaluate the overall performance for each group and for the two groups combined during the $3 \times$ and $1 \times$ conditions. Performance when the groups were combined was significantly better than chance during the $3 \times$ condition, $t(9)=2.83$, and during the $1 \times$ condition, $t(5)=6.68$. The results were mixed for the individual groups. The stay group was significantly above chance during the $3 \times$ condition, $t(4)$ $=3.19$, and the shift group was significantly above chance during the $1 \times$ condition, $t(2)=8.77$.

\section{Discussion}

The overall results clearly show above-chance performance at 24-hr retention intervals for nutcrackers in the radial maze analogue. Although the performance of nutcrackers was statistically above chance overall, it was only slightly above chance, averaging $54 \%$ during $3 \times$ testing and $58 \%$ during $1 \times$ testing. Although small, these effects may be theoretically significant when compared with the results reported by Hilton and Krebs (1990) for caching and noncaching parids (Parus spp). Performance of both caching and noncaching parids after 24-hr retention intervals continued to be above chance, but this was significant only for the caching parids. (No direct statistical comparison between caching and

Table 1. Percentage Correct for First Four Visits Following 24-hr Retention Interval for Birds That Received Three Trials per Week

\begin{tabular}{lcc}
\hline Group & Percentage correct & Binomial probability $^{\text {a }}$ \\
\hline Stay & & \\
Rudolph & 57.8 & .057 \\
Erwin & 56.9 & .082 \\
Helga & 56.0 & .114 \\
Hilda & 52.6 & .321 \\
Wolf & 50.0 & .537 \\
Shift & & \\
Esil & 52.6 & .321 \\
LeBeau & 50.0 & .537 \\
Klaus & 62.9 & .003 \\
Koenigb & 54.5 & .198 \\
Warner & 47.4 & .742 \\
\hline
\end{tabular}

a. Based on the first four visits for each of 29 trials per bird.

b. Total possible visits $=112$; see text. 
Table 2. Percentage Correct for the First Four Visits Following 24-hr Retention Interval for Birds That Received One Trial per Week

\begin{tabular}{|c|c|c|}
\hline Group & Percentage correct & Binomial probability ${ }^{a}$ \\
\hline \multicolumn{3}{|l|}{ Stay } \\
\hline Rudolph & 59.7 & .062 \\
\hline Erwin & 61.1 & .038 \\
\hline Helga $^{b}$ & 52.8 & .360 \\
\hline \multicolumn{3}{|l|}{ Shift } \\
\hline Esil & 58.3 & .097 \\
\hline LeBeau & 56.9 & .144 \\
\hline Klaus ${ }^{b}$ & 60.3 & .057 \\
\hline
\end{tabular}

a. Based on the first four visits for each of 18 trials per bird.

b. Total possible visits were 70 for Helga and 68 for Klaus; see text.

noncaching parids was reported.) The performance of nutcrackers was very similar to that of the caching parids. The relationship between memory ability and foraging ecology, that is, dependence on cached food, during nonforaging tasks still needs further study.

One interesting aspect of these results was the apparent improvement in performance from $3 \times$ to $1 \times$, especially for the nutcrackers in the shift group. It would appear that the major difference between the conditions was the opportunity for proactive interference, which was potentially much greater when the birds were tested three times per week. It would be interesting to collect more data focusing on this question.

\section{General Discussion}

In these experiments, excellent performance was obtained after long retention intervals in the radial maze analogue with different response strategies and unpredictable retention intervals. The results of Experiment 3 show that excellent retention was obtained when the retention intervals were tested in random order. Even when no information was available to the bird to predict which retention interval was being tested, performance remained at high levels. In addition, this procedure avoids the confound of retention interval with amount of experience that is present in many retention studies.

Performance was relatively independent of response strategy. Although there were small but consistent differences in performance as a function of response strategy, it was clear that nutcrackers could use remembered spatial locations to either return to or shift away from previously visited locations. This suggests that at least in some situations the spatial memory abilities of the nutcracker are flexible.

The shift group consistently performed better than the stay group throughout all four experiments. The statistical evidence suggests that the differences between these groups during two/four-hole acquisition may be replicable. However, the differences during four/eight-hole acquisition and throughout retention testing were clearly nonsignificant. This consistency may simply reflect the fact that the same birds were used throughout and the data obtained across experiments were not independent.
It is also possible that some factor might have affected the behavior of the groups differentially. For example, if nutcrackers have a slight bias toward shifting, this could have produced the small effects that were observed. Although the cause of the consistent performance differences might be interesting, there is one important fact. The retention of spatial information and the subsequent decline in performance as the retention interval increased were independent of response strategy. During Experiments 2-4, the performance of both groups decayed at the same rate. The adjusted percentage correct values obtained in Experiment 3 were about the same for both groups at the various retention intervals.

These results can be compared with the results of studies with other species. Both young (Olton \& Schlosberg, 1978) and adult (Olton \& Samuelson, 1976) rats tend to use the shift rule initially in the radial maze, and in young rats performance with the shift rule was better than performance with the stay rule. Rhesus monkeys (Macaca mulatta, Mishkin \& Delacour, 1975) and squirrel monkeys (Overman, et al., 1983) both learn nonmatching-to-sample (shift) faster than matching-to-sample (stay) when three-dimensional objects were used. Given the variation in both the species studied and the techniques used, further investigation of the effects of response strategies is needed.

Our studies of response strategy effects on performance during memory tasks in the Clark's nutcrackers are continuing. Basil, Olson, Kamil, and Balda (1993) investigated the differences between spatial matching-to-sample (stay) and nomatching-to-sample (shift) in an operant task. Early in acquisition the stay group performed better than the shift group, but this difference disappeared with continued training. The accuracy of both groups was the same during extensive retention testing.

The high levels of performance obtained during the current experiments have important comparative implications. We focus first on comparisons of nutcrackers and unrelated species and then on comparisons of nutcrackers and other corvids. The performance of nutcrackers in these experiments was much higher than any yet reported for pigeons (Spetch \& Edwards, 1986; Spetch \& Honig, 1988). More important, the results of these experiments can be compared with those of Hilton and Krebs (1990), who used variable retention intervals in a radial maze analogue with caching and noncaching parids. The performance of nutcrackers was generally higher than that observed in any of the parid species studied by Hilton and Krebs at shorter intervals (i.e., intervals from 0-180 min). However, Hilton and Krebs found performance significantly above chance for all species except noncaching birds after $24 \mathrm{hr}$ retention intervals. There was one potentially important procedural difference between these two experiments. Hilton and Krebs required the parids to return to a central perch between choices. In our experiments this was not required, but a central perch was available to the birds. The nutcrackers often returned to the perch, especially after taking a seed. A direct comparative study is needed, but this pattern implies that in the radial maze analogue paradigm, 24-hr retention in caching corvids and caching parids may be similar. 
This similarity between corvids and parids could be considered surprising. Field data have indicated differences in cache duration for parids and nutcrackers. The caches of some parids are usually recovered within 3 days (Stevens \& Krebs, 1986). Nutcrackers often do not recover caches for as many as 9 months (Vander Wall \& Hutchins, 1983). Differences in duration of memory for cache sites have been found in laboratory experiments. Hitchcock and Sherry (1990) found significant forgetting of cache-site location in less than 84 days. Balda and Kamil (1992) found little forgetting of cache-site locations after 285 days. Thus, one might have reasonably expected better long-term retention in the radial maze analogue in nutcrackers than in seedstoring parids.

This raises the question of the relationship between memory of natural cache sites and forgetting during arbitrary tests of spatial memory such as the radial maze analogue. How can nutcrackers remember cache sites for 285 days but largely forget radial maze sites after $24 \mathrm{hr}$ ? One possibility is that response strategy is important. During cache recovery, birds return to the remembered sites, whereas during the original radial maze analogue experiments (Balda \& Kamil, 1988), the birds were required to shift away from remembered sites. However, the results of the current experiments eliminate this possible explanation.

There are two factors that could contribute to performance differences in cache recovery and the radial maze analogue. First, spatial information may be either coded or stored differently, or both, when seeds are placed in cache sites than when seeds are removed from a radial maze analogue site. This may prove difficult to test directly. Second, proactive interference may be a much larger factor during radial maze analogue procedures than during cache-recovery procedures. In the radial maze analogue the list of to-beremembered sites changes almost daily. During cache recovery, the set of to-be-remembered cache sites does not change during any single experiment and only changes yearly in the field. The better performance observed during $1 \times$ testing than during $3 \times$ testing during Experiment 4 offers weak support for this idea. More direct tests of the role of proactive interference during both cache recovery and the radial maze analogue are needed.

Balda and Kamil (1989) compared the cache-recovery performance of the nutcracker and the scrub jay (Aphelocoma coerulescens), a corvid that is much less dependent on cached food than nutcrackers. In this controlled laboratory experiment, they found that nutcrackers recovered their caches more accurately than scrub jays, suggesting species differences in spatial memory abilities. Olson (1991) found that nutcrackers performed much better than scrub jays in an operant spatial nonmatching task, further supporting the existence of species differences between nutcrackers and scrub jays. It would be of great interest to test this hypothesis further by directly comparing nutcrackers and scrub jays in the radial maze analogue. If nutcrackers again outperform scrub jays, the evidence of consistent cross-situational species differences will clearly support the idea that nutcrackers possess an exceptional spatial memory ability that is general and is not limited solely to the cache-recovery problem.

\section{References}

Balda, R. P., \& Kamil, A. C. (1988). The spatial memory of Clark's nutcrackers (Nucifraga columbiana) in an analog of the radialarm maze. Animal Learning \& Behavior, 16, 116-122.

Balda, R. P., \& Kamil, A. C. (1989). A comparative study of cache recovery by three corvid species. Animal Behaviour, 38, 486-495.

Balda, R. P., \& Kamil, A. C. (1992). Long-term memory for cache site location in Clark's nutcrackers (Nucifraga columbiana). Animal Behaviour, 44, 761-769.

Basil, J. A., Olson, D. J., Kamil, A. C., \& Balda, R. P. (1993). The effects of response strategy and retention interval on performance of Clark's nutcrackers in a spatial operant task Unpublished manuscript.

Beatty, W. W., \& Shavalia, D. A. (1980). Spatial memory in rats: Time course of working memory and effect of anesthetics. Behavioral and Neural Biology, 28, 454-462.

Cole, S., Hainsworth, F. R., Kamil, A. C., Mercier, T., \& Wolf, L. L. (1982). Spatial learning as an adaptation in hummingbirds. Science, 217, 655-657.

Gill, F. B., \& Wolf, L. L. (1977). Nonrandom foraging by sunbirds in a patchy environment. Ecology, 58, 1284-1296.

Herrmann, T., Bahr, E., Bremner, B., \& Ellen, P. (1982). Problem solving in the rat: Stay vs. shift solutions on the three-table task. Animal Learning \& Behavior, 10, 39-45.

Hilton, S. C., \& Krebs, J. K. (1990). Spatial memory of four species of Parus: Performance in an open-field analogue of a radial maze. Quarterly Journal of Experimental Psychology, 42B, 345-368.

Hitchcock, C. L., \& Sherry, D. F. (1990). Long-term memory for cache sites in the black-capped chickadee. Animal Behaviour, 41, 701-712.

Kamil, A. C. (1978). Systematic foraging by a nectar-feeding bird, the Amakihi (Loxops virens ). Journal of Comparative and Physiological Psychology, 92, 388-396.

Kamil, A. C., \& Balda, R. P. (1990). Spatial memory in seed-caching corvids. In G. H.Bower (Ed.), The psychology of learning and motivation (Vol. 26, pp. 1-25). San Diego, CA: Academic Press.

Kamil, A. C., Balda, R. P., Olson, D. J., \& Good, S. (in press). Returns to emptied cache sites by Clark's nutcrackers: A puzzle revisited. Animal Behaviour

Mishkin, M., \& Delacour, J. (1975). An analysis of short-term visual memory in the monkey. Journal of Experimental Psychology: Animal Behavior Processes, 1, 326-334.

Olson, D. J. (1991). Species differences in spatial memory among Clark's nutcrackers, scrub jays, and pigeons. Journal of Experimental Psychology: Animal Behavior Processes, 17, 363-376.

Olson, D. J., \& Maki, W. S. (1983). Characteristics of spatial memory in pigeons. Journal of Experimental Psychology: Animal Behavior Processes, 9, 266-280.

Olton, D. S., \& Samuelson, R. J. (1976). Remembrance of places passed: Spatial memory in rats. Journal of Experimental Psychology: Animal Behavior Processes, 2, 97-116.

Olton, D. S., \& Schlosberg, P. (1978). Food-searching strategies of young rats: Win-shift predominates over win-stay. Journal of Comparative and Physiological Psychology, 92, 609-618.

Overman, W. H., McLain, C., Ormsby, G. E., \& Brooks, V. (1983). Visual recognition memory in squirrel monkeys. Animal Learning \& Behavior, 11, 483-488.

Roberts, W. A., \& Van Veldhuizen, N. (1985). Spatial memory in pigeons on the radial maze. Journal of Experimental Psychology: Animal Behavior Processes, 11, 241-260. 
Roitblat, H. L., Tham, W., \& Golub, L. (1982). Performance of Betta splendens in a radial arm maze. Animal Learning \& Behavior, 10, 108-114.

Sacks, R. A. (1973). Some characteristics of matching behavior in the Northern Bluejay (Cyanocitta cristata) Unpublished doctoral dissertation, University of Massachusetts at Amberst.

Spetch, M. L., \& Edwards, C. A. (1986). Spatial memory in pigeons (Columba livia) in an "open-field" feeding environment. Journal of Comparative Psychology, 100, 279-284.

Spetch, M. L., \& Honig, W. K. (1988). Characteristics of pigeons' spatial working memory in an open-field task. Animal Learning $\mathcal{E}$ Behavior, 16, 123-131.
Stevens, T. A., \& Krebs, J. R. (1986). Retrieval of stored food by marsh tits Parus palustris in the field. Ibis, 128, 513-525.

Vander Wall, S. B., \& Hutchins, H. E. (1983). Dependence of Clark's nutcracker, Nucifraga columbiana, on conifer seeds during the postfledging period. Canadian Field Naturalist, 97, 208-214.

Wunderle, J. M., Jr., \& Martinez, J. S. (1987). Spatial learning in the nectarivarous bananaquit: Juveniles vs. adults. Animal Behaviour, 35, 652-658. 